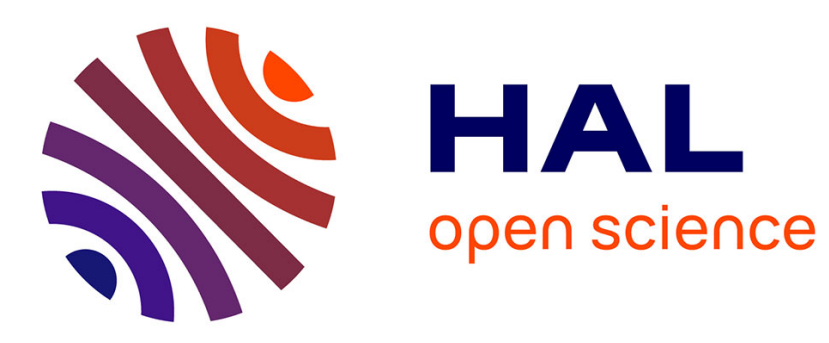

\title{
SAXS analysis of hyperstructure in carboxylato-telechelic poly(tert.butyl acrylate)'s
}

C. Maus, F. Fontaine, G. van den Bossche, R. Sobry, R. Jérôme

\section{To cite this version:}

C. Maus, F. Fontaine, G. van den Bossche, R. Sobry, R. Jérôme. SAXS analysis of hyperstructure in carboxylato-telechelic poly(tert.butyl acrylate)'s. Journal de Physique IV Proceedings, 1993, 03 (C8), pp.C8-67-C8-70. 10.1051/jp4:1993814 . jpa-00252245

\section{HAL Id: jpa-00252245 https://hal.science/jpa-00252245}

Submitted on 1 Jan 1993

HAL is a multi-disciplinary open access archive for the deposit and dissemination of scientific research documents, whether they are published or not. The documents may come from teaching and research institutions in France or abroad, or from public or private research centers.
L'archive ouverte pluridisciplinaire HAL, est destinée au dépôt et à la diffusion de documents scientifiques de niveau recherche, publiés ou non, émanant des établissements d'enseignement et de recherche français ou étrangers, des laboratoires publics ou privés. 


\title{
SAXS analysis of hyperstructure in carboxylato-telechelic poly(tert.butyl acrylate)'s
}

\author{
C. MAUS, F. FONTAINE*, G. VAN DEN BOSSCHE**, R. SOBRY* and R. JÉRÔME \\ Center for Education and Research on Macromolecules (CERM), Institute of Chemistry B6, University of \\ Liège, Sart-Tilman, 4000 Liège, Belgium \\ * Laboratory of Experimental Physics, Institute of Physics B5, University of Liège, Sart-Tilman, 4000 Liège, \\ Belgium \\ ${ }^{* *}$ Unité de Cristallographie, Institute of Physics B5, University of Liège, Sart-Tilman, 4000 Liège, Belgium
}

\begin{abstract}
A new class of Halato-Telechelic Polymers (HTP) has been prepared. Preleminary SAXS results on $\alpha, \omega$-carboxy poly (tert. butyl acrylate)s end-neutralized with $\mathrm{Ba}, \mathrm{Mg}$ and $\mathrm{Na}$ alkoxides show that the "ionic peak" usually observed in ionomers goes undetected. In contrast, a series of peaks appear at very low angles corresponding to Bragg spacings from 70 to $14 \mathrm{~nm}$. The successive peak positions are consistent with a hexagonal structure. In order to confirm this new experimental evidence, the effects of several parameters on the SAXS patterns have been investigated. Samples of various counterions and molecular weigths have been prepared under different conditions. Morphological changes have also been analyzed in the presence of a non-polar solvent (toluene).
\end{abstract}

\section{Introduction}

Ionomers are generally defined as polymers bearing a few ionic groups randomly distributed along a hydrophobic backbone. The ionic groups are strongly associated and form physical cross-links responsible for the unusual properties of ionomers. SAXS profiles exhibit a well defined peak (the "ionic peak"), considered as an evidence of microphase separation. This peak corresponds to Bragg spacings of the order of a few nanometers. An important upturn of intensity in the low scattering angle range is another characteristic of the SAXS patterns.

A new class of model ionomers has been developed in Liège: the Halato-Telechelic Polymers. HTP's are linear polymers bearing ionic groups only at both ends of the chains. These polymers of a welldefined molecular architecture show the same characteristic SAXS profile as the previously investigated ionomers.

$\alpha, \omega$ carboxylato poly(tert. butyl acrylate)'s have recently been prepared and investigated by SAXS. No clear evidence of an "ionic peak" has been found in a first set of experiments. A series of peaks however appears at very low angles corresponding to large Bragg spacings ranging from 70 to $14 \mathrm{~nm}$. The position of the peaks are consistent with a hexagonal structure (1). The large cross-sectional area of the tert.butyl side group of these polymers is supposed to modify the aggregation behaviour of the end-groups and to be responsible for the hyperstructure.

The aim of the present work is to confirm the hyperstructure in other poly(tert.butyl acrylate)'s and to study the influence of various parameters on this unusual morphology. 


\section{Experimental}

Polymers were prepared by living anionic polymerization followed by the quantitative neutralization of the $\alpha, \omega$-carboxy PtBA with metal alkoxides. SAXS measurements were performed with a Kratky compact camera proceeding by step scanning with a proportionnal counter. Slit-smearing effect was corrected using both Vonk (2) standard method and the method reported by Sobry et al. (3). The experiments dealing with solutions were performed on the lines D22 and D24 of the LURE-DCI synchrotron source at Orsay (France).

\section{Results and discussion}

All the experiments performed until now confirm the multi-peak structure of the new HTP's at low angles. A typical example of the SAXS curves is shown in Figure 1. The peak positions are the $s$ values of the maxima of the scattering curves obtained after substraction of a fitted basis line from the observed scattered intensity. The distance $\mathbf{d}$ corresponding to the observed peak position results from the Bragg relation $\mathbf{s}=\mathbf{1} / \mathbf{d}$. As discussed hereafter, the position of the peaks are in good agreement with an hexagonal hyperstructure. The theoretical ratio for a hexagonal structure are: $1 ; 1,73 ; 2,00 ; 2,65 ; 3,00 ; 3,46 ; 3,61$; 4,$00 ; 4,36 ; 4,58 ; 5,00 ; 5,20$. Some theoretical peak positions are not reported in tables 1 to 4 . This results on one hand from the overlapping of successive peaks and on the other hand from the weak intensity of some peaks. Previous experiments have shown that similar samples with $\mathrm{Na}$ as counterion only exhibit a few peaks [ 1].

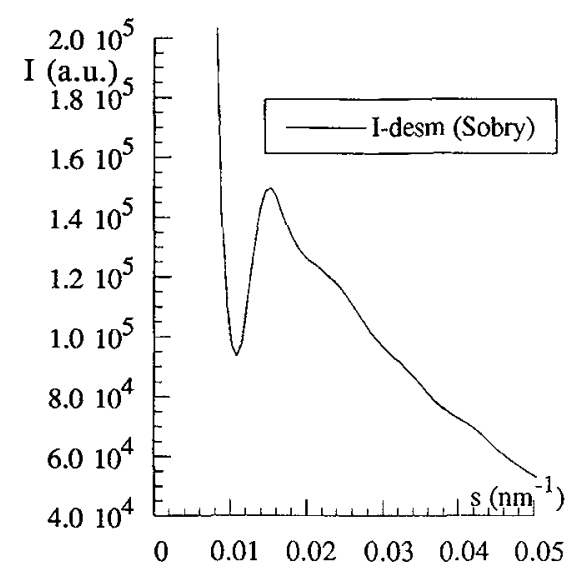

Figure 1. SAXS profile for Ba neutralized PtBA of molecular weight 23.000 ( 23-Ba)

\begin{tabular}{|c|c|c|c|}
\hline \multicolumn{4}{|c|}{$\begin{array}{l}\text { Distances corresponding to } \\
\text { observed peak positions (nm) }\end{array}$} \\
\hline $10^{\prime}$ & $20^{\prime}$ & $40^{\circ}$ & $60^{\circ}$ \\
\hline $\begin{array}{r}63,99 \\
39,53 \\
30,30 \\
23,64 \\
20,12 \\
\\
16,00\end{array}$ & $\begin{array}{l}63,32 \\
36,41 \\
28,05 \\
23,47 \\
19,23\end{array}$ & $\begin{array}{l}71,43 \\
48,78 \\
36,50 \\
28,17 \\
21,28\end{array}$ & $\begin{array}{l}83,56 \\
50,63 \\
37,20 \\
\\
28,85 \\
23,58 \\
19,92\end{array}$ \\
\hline \multicolumn{4}{|c|}{ Experimental ratio } \\
\hline $\begin{array}{l}1,00 \\
1,62 \\
2,11 \\
2,71 \\
3,18 \\
4,00\end{array}$ & $\begin{array}{l}1,00 \\
1,74 \\
2,26 \\
2,70 \\
3,29\end{array}$ & $\begin{array}{l}1,00 \\
1,46 \\
1,96 \\
2,54 \\
\\
3,36\end{array}$ & $\begin{array}{l}1,00 \\
1,65 \\
2,25\end{array}$ \\
\hline
\end{tabular}

Table 1

Increasing molding times are shown to shift the peak positions towards lower $\mathbf{s}$ values (table 1). Altough a structure of higher dimensions is formed under these conditions, the relative position of the peaks is essentialy independent of the molding conditions. The basic reason for this behaviour is still unclear but for comparison to be reliable all the samples must be molded under the same conditions.

The molecular weight of the prepolymer is another important parameter. An increase in the molecular weight of HTP's is well known to displace the ionic peak to lower s values. The position of the ionic peak depends on the mean distance between ionic domains, and thus on the molecular weight of the polymer: $S_{\max }$ is generally function of $\mathrm{M}_{\mathrm{n}}{ }^{-1 / 2}$ (4). However the molecular weight of the polymer has only a very small influence on the hyperstructure of PtBA based HTP's (table 2): the s value of the first peak increases only slightly with molecular weight and the hexagonal structure is maintained. There is actually no evident relation between hyperstructure and molecular weight. Interestingly, structures of "very high" dimensions appear to exist even for low molecular weight PtBA $\left(05-\mathrm{Ba}: \mathrm{M}_{\mathrm{n}}=5.000\right)$. 


\begin{tabular}{|c|c|c|c|c|c|}
\hline \multicolumn{6}{|c|}{ Distances corresponding to observed peak } \\
positions \\
(nm)
\end{tabular}

Table 2

\begin{tabular}{|c|c|c|c|c|}
\hline \multicolumn{5}{|c|}{$\begin{array}{c}\text { Distances corresponding to observed } \\
\text { peak }\end{array}$ positions } \\
(nm)
\end{tabular}

Table 3

If the influence of molecular weight is rather small, the polydispersity of the polymer surprisingly appears to be an important parameter. Polymers of a low polydispersity $\left(1,2\right.$ for $\mathrm{M}_{\mathrm{n}}=22.000$ and 1,3 for $\mathrm{M}_{\mathrm{n}}=23.000$ ) are shown in table 3 to present peaks at larger Bragg spacings than the more polydisperse systems $\left(1,6\right.$ for $\left.M_{n}=21.000\right)$. The same behaviour is observed for sodium neutralized polymers. Nevertheless the hexagonal structure is maintained in all the investigated samples. In conclusion, polymers of a narrower molecular weight distribution form structures of higher dimensions.

Nature of the cation has only little influence on the SAXS curves (5) of usual telechelic polymers (PBD's, polyisoprenes,...). Preliminary measurements on PtBA model ionomers show that the structure observed in the low $\mathbf{s}$ range is independent of the counterion. These results have been confirmed by investigating various alkaline-earth cations $(\mathrm{Mg}, \mathrm{Ca}, \mathrm{Sr}$ and $\mathrm{Ba}$ in table 4). Although a higher Bragg spacing is observed for $\mathrm{Ba}$, no clear trend emerges within the series. As a rule, $\mathrm{Na}$ leads to the biggest structures (table 3 ). The only effect of the metal cation has to be found in scattering peaks of a higher intensity when cations of a higher atomic mass are used (Barium).

\begin{tabular}{|c|c|c|c|}
\hline \multicolumn{4}{|c|}{$\begin{array}{c}\text { Distances corresponding to } \\
\text { observed peak positions }\end{array}$} \\
\hline 23Mm
\end{tabular}

Table 4

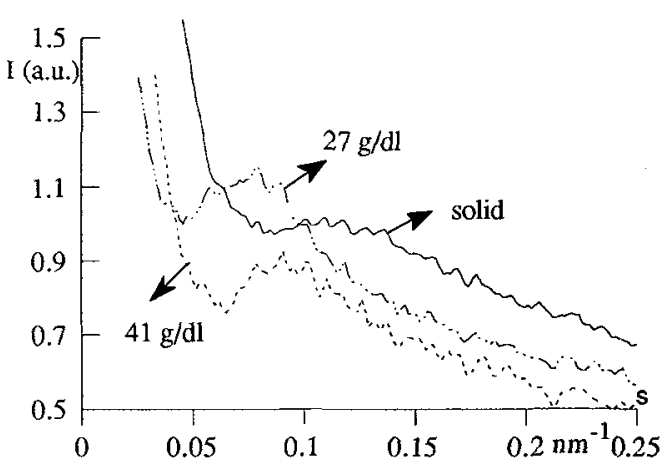

Figure 2 SAXS profiles for Ba neutralized PtBA ( $\mathrm{Mn}: 23000)$ in solid state and in toluene solution 
No clear evidence of an ionic peak in PtBA samples has been reported in the first experiments. However more recent investigations have shown that this peak is present in carboxylato poly(tert.butyl acrylate)'s. The peak is easily observed only when $\mathrm{Ba}$ is used as a counterion, probably because of the good contrast provided by this cation. The intensity of this peak remains weaker than for the previously investigated HTP's (Polystyrenes, PBD's, polyisoprenes,...) suggesting that the level of aggregation is lower in PtBA. This low level of aggregation is probably related to the important steric hindrance of the tert.butyl side groups limiting the ion pair aggregation.

The ionic peak is better defined in the presence of a non polar solvent (toluene in figure 2). As reported for polystyrene based HTP's, elsewhere in this issue, position of the ionic peak is shifted towards lower $\mathbf{s}$ values by swelling the polymer with increasing amounts of a solvent of a low polarity.

\section{Conclusions}

A hyperstructure in carboxylato-telechelic poly(tert.butyl acrylate)'s has been confirmed : a hexagonal structure has been observed in all the samples with a Bragg spacing ranging from 55 to $85 \mathrm{~nm}$ for the first observed peak. The bulkiness of the tert.butyl side group is probably responsible for the differences between the previously studied HTP's and PtBA's. Various parameters such as molding conditions, molecular weight, polydispersity and counterion have been investigated. Some modifications in the dimensions of the hyperstructure have been observed but the hexagonal structure is maintained. An ionic peak of low intensity has been observed in PtBA telechelics when $\mathrm{Ba}$ is the counterion.

At present time, there is no basic explanation for a hyperstructure in $\alpha, \omega$ metal carboxylato PtBA's in sharp contrast to all the other investigated carboxylato telechelics. Calculation of the multiplet size and the interfacial sharpness from the tail end of the curve is actually in progress. Furthermore, phase morphology of other HTP's bearing large side groups (like poly(tert.butyl styrene)'s) is under current investigation.

\section{References}

1.Fontaine, F.; Ledent, J.; Sobry, R.; François, E.; Jérôme, R.; Teyssié, P.: Macromolecules 1993, 26, 1480.

2. Vonk, C.G.: J. Appl. Cryst. 1971, 4, 340.

3. Sobry, R.; Rassel, Y.; Fontaine, F.; Ledent, J.; Liégeois, J.-M.: J. Appl. Crystallogr. 1991, 24, 692

4. Williams, C. E.; Russel, T.P.; Jérôme, R.; Horrion, J.: Macromolecules 1986, 19, 2877.

5. Ledent, J; Fontaine, F.; Reynaers, H.; Jérôme, R.: Polymer Bulletin 1985, 14, 461. 